\title{
Saúde Mental do Cuidador na Instituição Hospitalar
}

\author{
Juliana Bertoletti ${ }^{1}$ \\ Patrícia Martins Fagundes Cabral \\ Universidade do Vale do Rio dos Sinos
}

\begin{abstract}
RESUMO - Este artigo tem como propósito verificar as experiências laborais dos profissionais de enfermagem e suas conseqüências para a saúde mental desses trabalhadores. A pesquisa foi realizada junto a profissionais de enfermagem do Instituto de Cardiologia de Porto Alegre, afastados de suas atividades durante o ano de 2003 por transtornos mentais e comportamentais (episódios depressivos breves, transtornos depressivos recorrentes e ansiedade generalizada), diagnosticados de acordo com o CID 10. Os dados foram coletados através de entrevistas individuais semi-estruturadas, e para sua interpretação foi utilizada a técnica de Análise de Conteúdos. Os resultados mostram que aspectos do trabalho contribuíram no processo de adoecer desses profissionais, como a natureza das atividades do cuidador, sobrecarga de tarefas e dificuldades de relacionamento interpessoal. Verificou-se ainda a percepção dos indivíduos quanto ao papel da organização frente ao seu afastamento, de forma a ampliar a discussão sobre gestão de pessoas e promoção de saúde no trabalho.
\end{abstract}

Palavras-chave: saúde mental no trabalho; enfermagem; gestão de pessoas.

\section{Mental Health of the Caretaker in the Hospital Institution}

\begin{abstract}
This article has the purpose of verifying the laboural experiences of the nursing professionals and its consequences on their mental health. The research was made with nursing professionals of the Instituto de Cardiologia in Porto Alegre, who were dismissed from their activities during 2003 due to mental and behavioral disturbances (brief depressive disorder, recurrent depressive disorder and general anxiety), diagnosed according to CID-10. The data were collected through semi-structured individual interviews, and for their interpretation the technique of Content Analisys was used. The results show that aspects of work contributed to the process of falling ill of these professionals, such as the nature of the caretaker activities, overburden of tasks and dificulties of interpersonal relations. It was further verified the perception of the individuals as to the role of the organization vis-à-vis their dismissal, in order to increase the discussion about management of people and health promotion at work.
\end{abstract}

Key words: mental health at work; nursing; management of people.

O presente estudo visa investigar as relações entre indivíduo e trabalho, e suas conseqüências na saúde psíquica dos profissionais da enfermagem do Instituto de Cardiologia de Porto Alegre. A partir de uma pesquisa realizada nessa instituição, é propósito deste trabalho verificar de que forma as vivências laborais dos profissionais de enfermagem poderiam contribuir para o seu adoecimento psíquico.

Segundo conceito proposto por Dejours (1992), a saúde não compreende apenas uma sensação de bem-estar, mas um estado em constante movimento do qual procuramos nos aproximar, estando relacionada fundamentalmente ao desejo. Quando há perda do desejo, encontramo-nos diante de uma situação perigosa para o corpo e para a mente, correndo o risco de adoecimento físico e mental, o último manifestado por meio de estados de tristeza, apatia ou depressão.

Mas como manter o desejo de continuar produzindo quando o trabalho se torna fonte de insatisfação para o indivíduo? De acordo com Traverso-Yépez (2004), o trabalho

1 Endereço: Rua Coronel Bordini, 1153/501, Moinhos de Vento, Porto Alegre, RS, Brasil 90440-001. E-mail: julianab@portoweb.com.br constitui um espaço importante de relações interpessoais, a principal fonte de possibilidade de realização pessoal e sentido de segurança, de alternativas na variedade e qualidade de atividades e objetivos, bem como no desenvolvimento dos conhecimentos e capacidades. Assim, o trabalho representa um dos espaços de socialização e definição de identidades de maior importância na vida adulta.

A crescente especialização das atividades da enfermagem e a fragmentação do trabalho hospitalar introduzem elementos contraditórios na relação cuidador-cuidado, que podem ter efeitos nocivos sobre a saúde do trabalhador. Ao mesmo tempo em que o cuidado exige uma expressão de afeto adequada para lidar com os aspectos da dor e dependência do paciente, é também influenciado por três fatores inter-relacionados: o salário, meio de sobrevivência do trabalhador; o fantasma da perda do paciente, seja por alta-cura ou por alta-óbito, fato que instaura o conflito entre investir/desinvestir afeto nesta relação; e a obrigação de se colocar frente ao paciente como profissional, não lhe sendo permitido demonstrar preferências ou recusas, atração ou repulsa por este ou aquele paciente (Borsoi \& Codo, 1995).

Além disso, o cotidiano dos profissionais de saúde exige desses indivíduos o contato constante com a dor e a doença 
de seus pacientes, o que pode trazer como conseqüência uma sobrecarga emocional diária a esses trabalhadores. Neste sentido, o papel do cuidador se caracteriza pelo processo contínuo de vínculo ao paciente para que o ato de cuidar se torne possível, mesmo seguido da conseqüente perda, devido à sua melhora e alta ou porque "veio a óbito", expressão comumente utilizada entre esses profissionais.

A investigação da natureza do trabalho hospitalar, mais especificamente as atividades relacionadas à assistência dos pacientes, é relevante, visto que, permite uma melhor compreensão das vivências desses trabalhadores e dos aspectos da organização e do ambiente de trabalho que estariam contribuindo para o seu adoecimento e conseqüente incapacidade de continuar realizando suas funções, temporária ou permanentemente.

O processo de investigação orienta-se pelo pressuposto de que o "modo de adoecer" de um grupo de trabalhadores é engendrado pelo "modo de viver" dentro e fora das organizações. Logo, compreender a gênese, o desenvolvimento e a configuração de um dado perfil epidemiológico de uma população implica investigar os perfis produtivo (condições e relações socioprofissionais de trabalho) e reprodutivo (condições econômicas, sociais e culturais de vida fora do trabalho) (Ferreira, 2004, p.163).

Assim, este estudo tem como objetivo geral identificar quais os possíveis fatores relacionados à natureza, ao ambiente e à organização de trabalho que influenciam a ocorrência de afastamentos por licença-saúde entre os profissionais da enfermagem. Os objetivos específicos referem-se à percepção do indivíduo a respeito do seu processo de adoecimento, a relação deste com as atividades desenvolvidas na instituição hospitalar, as estratégias de enfrentamento utilizadas dentro do trabalho e durante o afastamento, bem como a percepção dos indivíduos sobre o papel da instituição junto ao funcionário.

\section{Método}

De acordo com dados obtidos no Setor de Pessoal do Instituto de Cardiologia em junho de 2004, a instituição possui um número de 1.380 funcionários. A equipe de enfermagem é composta por 257 auxiliares, 178 técnicos e 60 enfermeiros, entre funcionários efetivos e afastados, o que corresponde a $35,8 \%$ do total do quadro funcional da instituição.

Um levantamento realizado no Setor de Medicina do Trabalho do Instituto de Cardiologia revelou que 80 funcionários foram afastados de suas atividades durante o ano de 2003 , pelo período mínimo de 15 dias. Alguns destes estenderam-se para além desses dias, mediante pedido de encaminhamento ao INSS para licença saúde.

Essa pesquisa está baseada no fato de terem sido encontrados 14 funcionários afastados devido a transtornos mentais e comportamentais (episódios depressivos breves, transtornos depressivos recorrentes e ansiedade generalizada), entre os quais 12 são profissionais da área da enfermagem. Os indivíduos foram diagnosticados de acordo com classificação do CID 10 (Classificação Estatística Internacional de Doenças e Problemas relacionados à Saúde).
Os dados foram coletados por meio de entrevistas individuais semi-estruturadas realizadas com funcionários da enfermagem do Instituto de Cardiologia, sendo respeitada a sua vontade de participação por meio do Termo de Consentimento Livre e Esclarecido que foi disponibilizado. O roteiro que orientou a condução das entrevistas foi o seguinte:

1) Como você está se sentindo?

2) Você notou alguma melhora no seu estado no período em que esteve afastada?

3) Como você percebeu que estava adoecendo?

4) O que você acha que pode ter ocasionado este processo?

5) Como foi o impacto/conseqüências de sua doença no trabalho?

6) Você acha que de alguma forma o trabalho interferiu no seu adoecimento?

7) Como o hospital lidou com o seu processo de adoecimento?

8) Tem algo que você acha que o hospital poderia ter feito antes do seu adoecimento/afastamento? O quê?

9) Hoje como é a sua relação em equipe?

10) Qual o melhor aspecto de estar afastado do trabalho? E o pior?

11) Qual o nome da sua doença? Como é para você estar com___ (nome da doença)?

12) Você já cuidou de alguém com esse diagnóstico? Como foi?

Os profissionais que participaram da pesquisa são da área da enfermagem (técnicos e auxiliares) e constam no levantamento de funcionários afastados no período de 2003 com sintomas depressivos e/ou de ansiedade. Foi realizado primeiramente um contato telefônico com esses indivíduos, no qual foi verificado que apenas quatro entre os 12 profissionais haviam retornado às suas atividades profissionais. Os demais continuavam em licença-saúde pelo INSS e um havia se desligado da instituição.

Os quatro profissionais que participaram da pesquisa foram entrevistados em seu local de trabalho, durante o seu horário de expediente. Houve inicialmente um esclarecimento sobre os aspectos do sigilo e do uso das informações para os fins dessa pesquisa. Todos os profissionais entrevistados são do sexo feminino. Os relatos foram registrados em fita cassete para facilitar a transcrição das informações coletadas.

Para a tarefa de analisar e interpretar os dados foi utilizada a técnica de Análise de Conteúdos, a qual, segundo Minayo (2002), possui duas funções primordiais: a verificação de hipóteses e/ou questões e a descoberta do que está por trás dos conteúdos manifestos, indo além das aparências do que está sendo comunicado.

O projeto de pesquisa de origem foi aprovado pelo Comitê de Ética desta instituição em 16/06/04, de acordo com os preceitos que regulamentam as pesquisas envolvendo seres humanos. Os dados coletados foram utilizados somente para o que se referia aos objetivos da mesma, sendo as informações apresentadas de forma coletiva, sem qualquer prejuízo para as pessoas envolvidas, principalmente no que diz respeito a menção de nomes de pacientes ou profissionais de saúde envolvidos no atendimento destes. Os dados se encontram 
sob a guarda da pesquisadora, sendo garantido seu sigilo e confidencialidade.

\section{Resultados e Discussão}

Os dados serão apresentados em categorias, divididos de acordo com os conteúdos encontrados nas entrevistas que possibilitaram uma maior reflexão e aprofundamento da discussão sobre adoecimento e trabalho. As categorias são: 1) percepções sobre a natureza do trabalho e sua relação com o processo de adoecimento; 2) percepções sobre o ambiente e a organização do trabalho; 3) percepções sobre causas e impactos do adoecimento no trabalho; 4) percepções sobre o afastamento; e 5) percepções sobre o papel da instituição.

\section{Categoria 1 - Percepções sobre a natureza do trabalho e sua relação com o processo de adoecimento}

Nessa categoria, os depoimentos de duas entrevistadas apresentaram, de forma mais significativa, a grande preocupação com o domínio da técnica no desempenho de suas atividades profissionais. As entrevistadas referem que, de maneira geral, sua capacidade técnica ficou comprometida à medida que começaram a sentir os primeiros sinais de sofrimento psíquico. Verifica-se uma relação entre a natureza do trabalho e o processo de adoecer, exemplificado nos trechos a seguir:

"Eu queria sair porque eu achava que a pediatria estava me fazendo mal... Eu era totalmente atenciosa com as crianças, a pediatria exigia muito da minha cabeça." (Sujeito 1).

Provavelmente a referida exigência de atenção dispensada às crianças sinalize a necessidade de doação de afeto dessa trabalhadora, o que está para além do cuidado técnico. A situação de crianças hospitalizadas explicita, ainda mais, a dor e a fragilidade humana, despertando no trabalhador sentimentos que podem oscilar da compaixão à impotência. Diante disso, pode-se questionar: até que ponto esses profissionais são preparados, ao longo da sua formação profissional, para terem uma compreensão afetiva do sofrimento dos seus pacientes? Será que essa lacuna na preparação profissional, que geralmente acaba sendo preenchida por um excesso de racionalização, não é um dos fatores mais agravantes do sofrimento psíquico dos trabalhadores da enfermagem?

Esslinger, Kovács e Vaiciunas (2004) salientam a importância de espaços de reflexão destinados aos profissionais da saúde nas instituições hospitalares para que possam compreender melhor o processo de morte e de morrer inerente ao seu trabalho e intervir de forma mais humanizada junto aos pacientes.

É notória a dificuldade das entrevistadas para lidar com os aspectos emocionais do seu trabalho junto ao paciente e familiares. Alguns relatos referem o aparecimento de somatizações durante o processo de adoecimento, decorrentes de algum conflito na relação do indivíduo com o trabalho, refletindo uma dificuldade de elaboração psíquica e afetiva de situações vivenciadas no contexto profissional, como pode ser visto a seguir:
"Teve uma época aqui que eu faltei muito ao serviço, tava sempre no médico do trabalho, ou com dor de barriga, sempre era quando eu vinha trabalhar, ou vomitando ou com cefaléia, tinha muita rinite alérgica, e ele me afastava um ou dois dias." (Sujeito 2).

As somatizações não são raras em processos de adoecimento no trabalho, com vistas a dar conta da energia pulsional excedente que não encontra uma descarga adequada no trabalho e que, portanto, "transborda" para o corpo em forma de perturbações orgânicas (Dejours, 1994). O aparecimento de sintomas diversos, como cefaléia, problemas gástricos ou desordens de sono, podem estar sinalizando uma dificuldade do trabalhador em lidar com certos aspectos inerentes à sua atividade profissional, aspectos que na enfermagem estão contidos no papel de cuidar de outras pessoas.

Por isso, é de grande importância que o trabalhador de enfermagem esteja identificado com a função de cuidador e encontre prazer nessa atividade, pois uma descarga de energia psíquica adequada estaria resguardando o sujeito contra os riscos de adoecimento no trabalho. Quando as causas do estresse ocupacional se prolongam e os meios de enfrentamento do sujeito são escassos, o estresse pode avançar para fases de maior gravidade, tornando o corpo vulnerável a doenças diversas (Murta \& Tróccoli, 2004).

A funcionária refere ainda que as estratégias de defesa utilizadas pelo profissional de enfermagem para lidar com as demandas emocionais do paciente parecem não ser eficazes no seu cotidiano de trabalho:

“Apesar de ter essa questão de isolar o paciente, só cuidar, ir embora e esquecer, essas coisas assim, tu te envolve, acaba te envolvendo." (Sujeito 2).

É importante repensar a crença de que deixar as emoções na porta do trabalho seria a melhor maneira de evitar situações de conflito e sofrimento, especialmente quando a atividade exercida inclui o vigiar constante da vida e a morte dos pacientes, bem como acolher a angústia de familiares que aguardam pela recuperação dos mesmos. Nesse sentido, a valorização do capital humano nas instituições possibilita que os aspectos emocionais dos trabalhadores sejam incorporados nas atividades produtivas como um elemento positivo, elevando a competência das equipes de enfermagem em lidar com a pressão psicológica dos pacientes e familiares (Moscovici, 2001).

As exigências psicológicas que são feitas por pacientes e familiares à equipe de enfermagem se apresentam de modo sutil ou direto, e vão além do simples cuidado físico, das tomadas de pressão e da aplicação de medicações terapêuticas. É nesse sentido que o hospital é considerado como um espaço mítico em nossa sociedade, o qual, nessa condição, deve conter e administrar os problemas emocionais provocados pelo doente e sua doença e toda a rede de relações sociais vinculada a eles (Pitta, 1994). O profissional da enfermagem torna-se então o componente da equipe no qual são depositados todos os sentimentos e angústias despertadas pela doença, visto que ele é responsável pelo cuidado direto e contínuo ao paciente. 


\section{Categoria 2 - Percepções sobre o ambiente e a organização de trabalho}

As funcionárias, em sua maioria, referem em seus relatos que a escassez de pessoal nas equipes de enfermagem é um fator que prejudica a organização e a continuidade do trabalho, o que provoca uma sobrecarga diária de tarefas a esses profissionais. Alguns aspectos do relacionamento interpessoal foram afetados devido ao adoecimento, o que aparece por meio de agressividade e irritabilidade com colegas e pacientes, havendo também relatos de isolamento, tristeza e perda de prazer na interação com o grupo. Uma funcionária relata dificuldades de integração entre os membros da equipe, havendo queixa sobre a ausência de comunicação e cooperação no processo de trabalho.

"No bloco tem um número maior de funcionários, mas é muito difícil. Não há um trabalho, não há uma equipe no sentido amplo da palavra, entende, muito pelo contrário. Dá pra contar nos dedos os colegas que tu trabalha, que tu tens um amparo, um auxílio, que tu tens um coleguismo, pouquíssimos." (Sujeito 3).

A questão referida pela funcionária traz à tona um aspecto importante do mundo trabalho, visto que os problemas de relacionamento interpessoal têm peso considerável sobre o bem-estar e o rendimento do trabalhador, exercendo também influência significativa sobre o seu processo de adoecimento. Um bom instrumento para avaliar o nível de satisfação do funcionário em relação à organização é a pesquisa de clima, o qual, segundo Fagundes (2000), traz elementos importantes para a compreensão da organização em seus aspectos manifestos e latentes, oportunizando mudanças na empresa a partir do levantamento das opiniões e percepções das pessoas que a compõe.

Nesse sentido, é importante que a instituição possa avaliar seus procedimentos em relação à gestão e ao desenvolvimento de pessoas na organização, procurando adotar práticas que valorizem a participação dos indivíduos no processo de mudanças organizacionais. Quando bem planejada e monitorada, a investigação do clima vem a cumprir essa função, visto que pode detectar os aspectos culturais vigentes que estariam influenciando a satisfação e a motivação do funcionário, bem como avaliar as deficiências de comunicações e relações internas (Fagundes, 2000).

Verifica-se ainda que a organização do trabalho impacta no aparecimento de sintomas depressivos que ficaram acentuados após um aumento de carga horária, como relata uma das entrevistadas, funcionária do turno noturno:

\footnotetext{
"Nós tínhamos uma carga horária, e quando a gente trocou houve uma mudança muito grande na minha vida. Foi troca de horário, troca de colegas, então eu percebi que foi bem nessa época que eu comecei a me sentir triste. Eu estranhei muito essa mudança, eu fiquei muito mal." (Sujeito 1).
}

A funcionária relata ainda que o aumento da carga horária acarretou em fadiga e insônia constantes, o que prejudicou tanto a sua vida profissional quanto a relação em família. Silva (1990) afirma que a ansiedade ocasionada pela in- tensificação do ritmo de trabalho é agravada sempre que existem riscos no trabalho, o que, no caso da enfermagem, é percebido por meio do nível de responsabilidade envolvido na função do cuidador.

São inúmeros os fatores de risco encontrados em certos ambientes de trabalho, sejam eles físicos, químicos, biológicos, ergonômicos ou psicossociais. No interior de uma instituição hospitalar esses fatores se apresentam a todo instante para o profissional da enfermagem por ser o componente da equipe que se envolve de forma mais direta com a manipulação dos aparelhos, aplicação de medicações e cuidados especiais dos pacientes. Segundo Murta e Tróccoli (2004), o estresse pode ser entendido como uma reação adaptativa do organismo humano, com componentes físicos e psicológicos, resultantes da exposição a situações que excedem os recursos de enfrentamento da pessoa.

Stacciarini e Tróccoli (2004) salientam ainda que o fenômeno do estresse ocorre de forma diferenciada para cada indivíduo, assim como as estratégias de enfrentamento devem ser adaptadas para o indivíduo de acordo com as particularidades do seu contexto profissional. Nesse sentido, a mesma profissão pode gerar níveis distintos de estresse em decorrência das características próprias da personalidade de cada um, as quais, por sua vez, levam a interações diferenciadas com o ambiente.

À medida que vê sua capacidade de atenção e concentração diminuídas, o trabalhador passa a ter medo de acidentes, o que foi relatado por esta funcionária como o medo de errar uma medicação ou uma dose e pôr em risco a vida do paciente. A possibilidade de prejudicar o paciente pode provocar, por si só, um alto nível de estresse emocional ao profissional da enfermagem.

Segundo Pitta (1994), existem alguns aspectos irreconciliáveis no regime de turnos - e o noturno em especial - que trazem desordens na esfera biológica, psicológica e social desses trabalhadores e seus familiares, havendo prejuízo dos ritmos circadianos e um descompasso entre sincronizadores individuais e sociais. Além disso, o regime de turnos e plantões abre a possibilidade de uma dupla jornada de trabalho em diferentes empregos, o que é prática comum entre os trabalhadores da área da saúde.

A qualidade de vida no trabalho, portanto, deve ser resgatada por meio da realização de melhorias na organização do trabalho que visem suprir as necessidades e expectativas dos trabalhadores, assentadas na idéia de humanização do trabalho e na responsabilidade social da empresa (Fernandes, 1996). A implementação de políticas de gestão voltadas para a qualidade de vida do trabalhador minimiza os problemas ligados à insatisfação no trabalho, aumentando conseqüentemente a produtividade e a eficiência dos trabalhadores, objetivos finais da organização.

\section{Categoria 3 - Percepções sobre causas e impactos do adoecimento no trabalho}

As funcionárias entrevistadas demonstraram uma boa percepção quanto ao processo de adoecimento, havendo clareza sobre os eventos que possivelmente ocasionaram e/ou contribuíram para o afastamento do trabalho. Duas funcionárias relatam a ocorrência de acidentes de trabalho 
com pacientes HIV positivo que desencadearam episódios depressivos acompanhados de um movimento de evitação do ambiente hospitalar, como no recorte abaixo:

"Foi em decorrência deste acidente que eu entrei em depressão. Eu não dormia de noite, tinha ansiedade direto, e com medo de fazer as coisas, medo de entrar no hospital, medo de morrer. E aí ele (o médico do trabalho) me afastou." (Sujeito 2)

Os acidentes de trabalho com pacientes HIV positivo exigem que o funcionário se submeta ao tratamento com coquetel antiretroviral, o que impede que ele seja contaminado pelo vírus da AIDS. Entretanto, o coquetel apresenta efeitos colaterais que se manifestam por meio de perturbações digestivas, podendo causar ainda mudanças de humor nos primeiros dias de aplicação.

Além das alterações orgânicas decorrentes do uso do coquetel, o profissional que se acidenta nessa situação experimenta de perto a ameaça da contaminação e conseqüentemente sente medo e ansiedade de entrar novamente em contato com os riscos oferecidos pelo seu ambiente de trabalho. A percepção do risco de vida gera sentimentos de impotência e revolta no trabalhador, como relata outra funcionária acidentada:

"Se tu pega uma doença sem ter culpa daí a gente se deprime. Tu pensa, pô, não fiz nada pra isso, o que eu fiz pra merecer uma coisa dessas? Tu toma aquilo infelizmente como um castigo." (Sujeito 4).

Os avanços das pesquisas sobre a AIDS têm contribuído com o esclarecimento e a prevenção das formas de contaminação do vírus HIV. A transmissão do HIV no ambiente de trabalho é denominada transmissão ocupacional, atingindo principalmente os profissionais da saúde em contato direto com os pacientes. Alguns fatores podem influir no risco da transmissão ocupacional, como a prevalência da infecção pelo HIV na população de pacientes, o grau de experiência dos profissionais de saúde no cuidado desse tipo de paciente, o uso de equipamentos de proteção adequados (luvas, óculos de proteção, máscaras, aventais, etc.), bem como a frequiência de utilização de procedimentos invasivos (GAPA-RS, 2004).

A fala da funcionária expressa ainda a sua percepção de que o doente seria o responsável por "ter pegado" a doença, havendo uma conotação de doença como "castigo" para aqueles que fizeram algo que os tornaram merecedores de tal punição. Como esse sentimento, mesmo que inconsciente, pode ter impacto na relação cuidador-cuidado?

Esslinger e cols. (2004) afirmam que os profissionais de saúde, ao escolher sua profissão, de forma mais ou menos consciente, estão lidando com aspectos do adoecer que se relacionam com a sua forma pessoal de lidar com perdas, dor e morte. Assim, o autoconhecimento desses profissionais é um aspecto pouco discutido nos cursos de formação e nas instituições hospitalares, mas essencial para que possam estabelecer uma relação de empatia com o sofrimento do paciente. A capacidade de colocar-se no lugar do outro viabiliza um cuidado comprometido com uma postura ética, minimizando a situação de desamparo que a doença suscita no paciente.
Os acidentes de trabalho, juntamente com o absenteísmo, são problemas que afetam a produtividade, sendo de interesse dos gestores encontrar soluções para tais questões. Entretanto, as informações transmitidas para os trabalhadores, bem como as teorias adotadas pelos serviços de Medicina do Trabalho, parecem estar dirigidas para uma culpabilização do trabalhador, numa abordagem reducionista que desconsidera as situações de fadiga e sofrimento mental ligados ao trabalho, com conseqüente aumento de falhas no desempenho (Silva, 1990).

Os relatos revelam ainda que, entre todos os medos que se misturam no trabalhador, o medo da demissão se manifesta por meio da dificuldade em expor o adoecimento para a chefia e supervisores, de não ser considerado capaz para exercer suas atividades, o que aparece acompanhado da sensação de não corresponder às expectativas da instituição.

"Eu já tive medo também de conversar sobre isso, porque aí tu tá dentro do teu ambiente de serviço e daí eles não vão querer mais uma pessoa deprimida aqui dentro." (Sujeito 2).

"Eu trazia um livro e fazia de conta que estava lendo pras pessoas não falarem comigo... Quando eu cheguei ao ponto de admitir que eu estava doente e me afastar, foi uma surpresa pra todo mundo.” (Sujeito 1).

Pitta (1994) afirma que o adoecer na sociedade ocidental contemporânea significa deixar de produzir, sendo, portanto, o mesmo que deixar de ser. A partir dessa perspectiva, o processo de reconhecer-se doente implica em aceitar uma situação vergonhosa para o indivíduo, sendo o silêncio e o isolamento as estratégias encontradas por esses trabalhadores para protegerem-se diante do processo de exclusão, uma vez que seu adoecimento viesse a público.

Os medos que os profissionais relataram frente ao afastamento revelam um aspecto que deve ser considerado pela instituição, que diz respeito aos processos de comunicação interna e visibilidade do funcionário dentro da organização. A principal dificuldade está contida no medo de expor o adoecimento e ser prejudicado de alguma forma, mostrando a falha dos gestores em estabelecer uma relação de proximidade e confiança com o seu funcionário. $\mathrm{O}$ silêncio dos funcionários pode ser uma reação ao que é comunicado pela cultura organizacional, mais preocupada com a competência dos profissionais enquanto força de trabalho, e pouco atenta em desenvolver um vínculo de reciprocidade com eles, no qual os objetivos individuais e organizacionais possam ser atendidos.

\section{Categoria 4 - Percepções sobre o afastamento}

O período de afastamento foi sentido pela maioria das entrevistadas como uma fase difícil de vida, embora necessária para a sua recuperação e retorno ao trabalho. Alguns relatos mostram que o afastamento propiciou um período produtivo, de crescimento pessoal e reavaliação de valores, em que o indivíduo expressa a dimensão que o trabalho ocupa em sua vida:

"Eu vi várias coisas que eram importantes pra minha vida e que eu não fazia, não via, não aproveitava. Tipo ver os amigos, sair, 
ir numa academia, ver a luz do dia, porque eu passo o tempo inteiro dentro do hospital trabalhando." (Sujeito 2).

Ao distanciar-se de uma rotina de trabalho que ocupava grande parte de seu tempo, a funcionária parece ter reencontrado o prazer nas atividades sociais e de lazer, fundamental para a manutenção do equilíbrio psíquico das pessoas. $\mathrm{O}$ indivíduo que canaliza todas as suas energias para o trabalho não tem tempo para cuidar de si, perde em qualidade de vida e aumenta as suas chances de adoecer em decorrência da fadiga.

Existem variáveis situacionais que podem influenciar na ocorrência de estresse ocupacional, como a qualidade das redes sociais encontradas dentro e fora do trabalho. É importante que a vida cotidiana da organização esteja respaldada por um suporte social bem desenvolvido, visto que isso tem um efeito protetor que contribui para reduzir os níveis de estresse no trabalho (Tamayo, Lima \& Silva, 2002). Outras variáveis que não estão diretamente relacionadas ao âmbito organizacional, como a atividade física regular, têm uma influência benéfica na redução de substâncias fisiológicas ligadas ao estresse. Certas modalidades de atividade física proporcionam ainda a possibilidade de interação social e comunicação interpessoal, servindo de estratégias para lidar com situações estressantes (Tamayo, 2001).

Verifica-se também nessa categoria, relatos do afastamento como um período negativo, no qual o indivíduo sentiu-se privado de sua condição de ser produtivo, demonstrando a importância do trabalho para sua estruturação psíquica:
"Eu sentia muita falta, aquela coisa de levantar cedo, tomar meu banho, me arrumar, eu vinha com vontade de trabalhar, desempenhava minha função." (Sujeito 3).

A fala mostra que o trabalho representa para esse indivíduo um meio de reconhecer-se como alguém que existe e tem importância para outros ao desempenhar sua função na enfermagem, o que lhe confere um lugar como sujeito social e psicológico (Mendes \& Morrone, 2004). Ao parar de produzir, o indivíduo parece se sentir à margem da sociedade, havendo uma conotação do afastamento como um período de exclusão e perda da identidade que ele encontra por meio do exercício profissional.

Nesse sentido, é importante que a instituição mantenha o vínculo com o funcionário no período do afastamento, por meio de políticas de gestão voltadas para a saúde do trabalhador. A participação de serviços sociais, realizando visitações aos trabalhadores afastados bem como a realização de grupos terapêuticos e/ou atendimentos por parte do Serviço de Psicologia, são estratégias que podem ser implementadas como parte de uma política de gestão comprometida com o trabalhador. $\mathrm{O}$ vínculo com o funcionário afastado é uma maneira de a organização exercer sua responsabilidade social, acolhendo-o nesse período difícil de vida e possibilitando o início de um processo de humanização no trabalho.

\section{Categoria 5 - Percepções sobre o papel da instituição}

Quanto ao posicionamento da instituição frente ao processo de adoecimento e afastamento das funcionárias, há relatos

Quadro 1. A relação entre trabalho e sofrimento psíquico nos profissionais da enfermagem: quadro síntese dos resultados da pesquisa.

\begin{tabular}{|c|c|}
\hline Categoria & Aspectos principais \\
\hline Categoria 1 & $\begin{array}{l}\text { - } \quad \text { Adoecimento acompanhado de somatizações (dores articulares, alergias, alterações digestivas, entre outras). } \\
\text { - } \quad \text { Dificuldade de elaboracão afetiva e psíquica das situacões de trabalho. }\end{array}$ \\
\hline $\begin{array}{l}\text { Percepções sobre a natureza do trabalho } \\
\text { e o processo de adoecimento }\end{array}$ & $\begin{array}{l}\text { - } \quad \text { Ausência de preparação, na formação profissional, para lidar com demandas afetivas dos pacientes. } \\
\text { - } \quad \text { Dificuldade de lidar com a pressão psicológica da equipe, pacientes e familiares. } \\
\text { Perda de prazer no exercício da profissão. }\end{array}$ \\
\hline
\end{tabular}

\section{Categoria 2}

Percepções sobre o ambiente e a orga- - Dificuldade de interação devido ao adoecimento (irritabilidade, tristeza e isolamento).

nização de trabalho

- Estados de fadiga, insônia e depressão decorrente da sobrecarga de trabalho.

- Importância do relacionamento interpessoal como propiciador de bem-estar no trabalho.

Categoria 3 - Causas do adoecimento têm estreito vínculo com a situação de sofrimento no trabalho.

- Estratégia do silêncio para evitar a exclusão na relação com a equipe e superiores.

Percepções sobre causas e impactos de • Medo de pôr em risco a vida do paciente e a sua própria.

adoecimento $\quad$ - Medo da demissão.

Categoria 4

Percepções sobre o afastamento
- $\quad$ O afastamento é visto como período importante para a recuperação e retorno ao trabalho.

- O afastamento é considerado como uma fase de crescimento pessoal positiva.

- Parar de produzir implica em aumento de ansiedade para o trabalhador.

\section{Categoria 5}

Percepções sobre o papel da instituição
- Dificuldade de comunicação entre chefia e o setor de Recursos Humanos.

- Fragilidade das condições de diálogo entre funcionários e superiores.

- O funcionário não procura o Serviço de Psicologia pois tem medo de ser perseguido em seu emprego. 
sobre o bom atendimento da equipe responsável pela área de Recursos Humanos, demonstrando o comprometimento dos profissionais com o acompanhamento do funcionário durante esse processo.

"Desde a minha chefe, a psicóloga, o médico do trabalho, todos me atenderam bem. Não tenho o que reclamar, fui muito bem atendida." (Sujeito 1).

Entretanto, há depoimentos que mostram a visão do funcionário sobre a filosofia da empresa, expressando ainda o desapontamento com as condições de diálogo e as políticas de assistência ao trabalhador na instituição.

"Os hospitais, eu acho bom que eles tenham psicólogos assim, e que ofereçam pra nós, mas eu acho que tem que ser divulgado de uma forma que nos dê confiança de conversar." (Sujeito 2).

As mudanças cada vez mais aceleradas do panorama sócio-econômico têm levado as organizações a estudar o tema da confiança como um recurso mais eficaz nas relações de trabalho do que os sistemas utilizados nas estruturas organizacionais tradicionais. A funcionária coloca a falta de "divulgação" como fator importante para a construção da confiança, ou seja, é preciso que a organização promova uma imagem de si como "digna de confiança", ativando procedimentos para a circulação e transparência das informações, o que aumentará a base de conhecimentos necessária para que os indivíduos possam fazer sua própria avaliação sobre a empresa. Apesar de não ser tarefa simples, a construção de laços de confiança confere maior visibilidade e dinamismo nas relações dentro das organizações, sendo importante promovê-la de modo ativo e intencional (Farnese, 2004).

Nesse sentido, os psicólogos devem construir um espaço de escuta na intersecção entre o coletivo e as singularidades individuais por meio da inserção ativa nas equipes de trabalho e da articulação de seu saber com outras áreas de conhecimento. Em sua função facilitadora dos processos de comunicação, a Psicologia permite a "oxigenação" das relações dentro da empresa, abrindo brechas no discurso instituído, possibilitando a superação de paradigmas ultrapassados e a agregação de novos valores à cultura organizacional.

No Quadro 1 são apresentados os principais resultados em cada categoria pesquisada.

\section{Considerações Finais}

Os dados apresentados nas cinco categorias mostram que alguns aspectos do trabalho do profissional da enfermagem estão associados às causas do seu adoecimento. Foi possível constatar, por meio do baixo número de funcionários que haviam retornado ao trabalho, que os afastamentos prolongados representam uma situação freqüente nessa instituição, o que pode trazer como conseqüência um prejuízo na qualidade do

Os relatos das funcionárias entrevistadas mostram que o afastamento do trabalho foi vivenciado como um período de sentimentos contraditórios, sendo reconhecido como uma etapa positiva e importante para a sua recuperação, mas ao mesmo tempo sendo relacionado com o aumento de ansiedade. $\mathrm{O}$ fato de não estarem produzindo, mesmo que tempora- riamente, levou algumas entrevistadas a se sentirem privadas de sua condição de sujeito, o que demonstra a relevância do trabalho na estruturação psíquica do indivíduo.

É necessário que a instituição priorize em sua filosofia de trabalho o desenvolvimento da competência emocional das equipes, habilitando o cuidador a lidar com a pressão psicológica de pacientes e familiares com menor custo à sua saúde psíquica. A criação de espaços de reflexão destinados aos profissionais da saúde pode ser uma estratégia de prevenção da instituição, à medida que possibilita um espaço de identificação e troca de idéias, propiciando o autoconhecimento desses profissionais e beneficiando a relação cuidador-cuidado. Para tanto, é fundamental também investir no desenvolvimento de competências gerenciais, isto é, capacitar as lideranças das equipes de enfermagem para se apropriarem do papel de gestores, compreendendo melhor as questões do sofrimento psíquico no trabalho que impactam em suas equipes.

O serviço de Psicologia pode contribuir com a política de gestão de pessoas por meio de uma maior compreensão da subjetividade do trabalhador, recolocando o capital humano como principal recurso a ser investido pela organização. Para tanto, os psicólogos devem inserir-se ativamente nos grupos de trabalho, agenciando melhores condições de diálogo e articulando seu conhecimento com outros saberes, de forma que a saúde e o bem-estar do trabalhador sejam valorizados e vivenciados, cotidianamente, como princípios da instituição.

\section{Referências}

Borsoi, I. C. F. \& Codo, W. (1995). Enfermagem, trabalho e cuidado. Em W. Codo \& J. C. Sampaio (Orgs.), Sofrimento psíquico nas organizações: saúde mental e trabalho (pp.139151). Petrópolis: Vozes.

Dejours, C. (1992). A loucura do trabalho: estudos de psicopatologia do trabalho. São Paulo: Cortez.

Dejours, C. (1994). A carga psíquica do trabalho. Em M. S. Betiol (Org.), Psicodinâmica do trabalho: contribuições da escola Dejouriana à análise da relação prazer, sofrimento e trabalho (pp. 21-32). São Paulo: Atlas.

Esslinger, I., Kovács, M. J. \& Vaiciunas, N. (2004). Cuidando do cuidador no contexto hospitalar. O Mundo da Saúde, 28(3), 277-283.

Fagundes, P. M. (2000). A pesquisa de clima organizacional como instrumento de mudança: um estudo de caso. Revista Arché Interdisciplinar: inovação e mudança, 9(28) 127-152.

Farnese, M. L. (2004). A construção da confiança nas organizações. Em A. S. Laner \& J. B. Cruz (Orgs.), Repensando as organizações: da informação à participação (pp. 93-126). Florianópolis: Fundação Bortoux.

Fernandes, E. C. (1996). Qualidade de vida no trabalho: como medir para melhorar. Salvador: Casa da Qualidade.

Ferreira, M. C. (2004). Marcas do trabalho e bem-estar no serviço de atendimento ao público. Em A. M. Mendes \& M. C. Ferreira (Orgs.), Trabalho em transição, saúde em risco (pp. 163-183). Brasília: Editora Universidade de Brasília.

GAPA (2004). Grupo de Apoio a prevenção da AIDS no Rio Grande do Sul. Apresenta informações sobre HIV. Retirado em 07/10/2004, http//www.gapars.com.br 
Mendes, A. M. \& Morrone, C. F. (2004). Vivências de prazersofrimento e saúde psíquica no trabalho: trajetória conceitual e empírica. Em A. M. Mendes \& M. C. Ferreira (Orgs.), Trabalho em transição, saúde em risco (pp.27-42). Brasília: Editora Universidade de Brasília.

Minayo, M. C. (Org.) (2002). Pesquisa social: teoria, método e criatividade. Porto Alegre: Vozes.

Moscovici, F. (2001). A organização por trás do espelho: reflexos e reflexões. Rio de Janeiro: José Olympio.

Murta, S. G. \& Tróccoli, B. T. (2004). Avaliação de intervenção em estresse ocupacional. Psicologia: Teoria e Pesquisa, 20(1), 39-47.

Paschoal, T. \& Tamayo, A. (2005). Impacto dos valores laborais e da interferência família: trabalho no estresse ocupacional. Psicologia: Teoria e Pesquisa, 21(2), 173-180.

Pitta, A. (1994). Hospital: dor e morte como ofício. São Paulo: Hucitec.

Silva, E. S. (1990). Saúde mental e trabalho. Em S. A. Tundis \& N. do R. Costa (Orgs.), Cidadania e loucura: políticas de saúde mental no Brasil (pp. 218-283). Porto Alegre: Vozes.

Stacciarini, J. M. \& Tróccoli, B. T. (2004). Estresse ocupacional. Em A. M. Mendes \& M. C. Ferreira (Orgs.), Trabalho em transição, saúde em risco (pp. 187-205). Brasília: Editora Universidade de Brasília.
Tamayo, A. (2001). Prioridades axiológicas, atividade física e estresse ocupacional. Revista de Administração Contemporânea, 5(3), 127-147.

Tamayo, A., Lima, D. \& da Silva, A. V. (2002). Impacto do clima organizacional sobre o estresse no trabalho [Trabalho completo]. Em Associação Nacional de Pós-Graduação e Pesquisa em Administração (Org.), Anais, XXVI Encontro da Associação Nacional de Pós-Graduação e Pesquisa em Administração (pp. 46-59). Salvador: ANPAD.

Traverso-Yépez, M. A. (2004). Trabalho e saúde: subjetividade em um contexto de precariedade. Em A. M. Mendes \& M. C. Ferreira (Orgs.), Trabalho em transição, saúde em risco (pp. 111-131). Brasília: Editora Universidade de Brasília.

Recebido em 01.06.2005

Primeira decisão editorial em 13.04.2006

Versão final em 10.05.2006

Aceito em 26.01.2007 